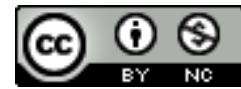

Jurnal Pendidikan Ilmu Pengetahuan Sosial Indonesia is licensed under A Creative Commons Attribution-Non Commercial 4.0 International License.

\title{
Penerapan Model Pembelajaran Inside Outside Cirle Terhadap Hasil Belajar Siswa SMA Negeri 6 Pontianak Timur
}

\author{
Ivan Veriansyah $^{1)}$, Adhitya Prihadi ${ }^{2)}$, Rosanti $^{3)}$ \\ ${ }^{1)}$ IKIP PGRI Pontianak, Pontianak, Indonesia \\ Email : ivanveriansyah@gmail.com \\ ${ }^{2)}$ IKIP PGRI Pontianak, Pontianak, Indonesia \\ Email : aditlaa929@gmail.com \\ ${ }^{3)}$ IKIP PGRI Pontianak, Pontianak, Indonesia \\ Email : rosanti_30@yahoo.co.id
}

\begin{abstract}
Abstrak. Penelitian ini bertujuan untuk mengetahui pengaruh dari penerapan model pembelajaran inside outside circle pada pelajaran Geografi pada siswa kelas X SMA Negeri 6 Pontianak. Populasi dalam penelitian ini adalah seluruh siswa kelas X di SMA Negeri 6 Pontianak yang terdiri dari 5 kelas. Sedangkan sampel pada penelitian ini adalah siswa di kelas XB dan XE. Penelitian ini menggunakan Quasi Experimental Design dengan rancangan penelitian two group post test only. Adapun hasil dari penelitian ini adalah 1) nilai rata-rata siswa pada pelajaran geografi pada kelas control atau kelas yang tidak diterapkan metode inside outside circle adalah sebesar 67,6 dengan kategori "cukup". 2) nilai rata-rata siswa pada pelajaran geografi pada kelas eksperimenatau kelas yang menerapkan metode inside outside circle adalah sebesar 70,6 dengan kategori "baik". 3) Terdapat pengaruh penerapan model pembelajaran Inside Outside Circle terhadap hasil belajar siswa pada mata pelajaran geografi kelas X SMA Negeri 6 Pontianak dengan nilai hasil Uji U Mann Whitney Asymp Sig. (2-tailed) = 0,027 < 0,050.
\end{abstract}

Kata kunci : Inside Outside Circle; Hasil Belajar

\section{PENDAHULUAN}

Perkembangan zaman dan teknologi yang semakin pesat dan kompetitif menuntut pendidikan di Indonesia harus mampu menciptakan generasi yang berkompeten. . Keadaan semacam itu pada gilirannya akan menuntut para pelaksana dalam bidang pendidikan di berbagai bidang untuk menjawab tuntutan tersebut melalui fungsinya sebagai guru. Guru merupakan ujung tombak yang berada pada garis terdepan yang langsung berhadapan dengan siswa melalui kegiatan pembelajaran di kelas maupun di luar kelas(Yuliana, Barlian, \& Jaenuddin, 2018)

Guru dituntut untuk terus berinovasi demi terus meningkatkan kualitas pembelajaran yang dapat menuju hasil pembelajaran yang maksimal pula, setiap siswa berhak mengembangkan keterampilan yang ia miliki (Malasari, Nindiasari, \& Jaenudin, 2017). Salah satu inovasi yang dapat dilakukan adalah dengan cara menerapkan model pembelajaran yang sesuai dengan kebutuhan siswa dankemajuan siswa dalam mengupayakan tujuan pembelajaran yang diharapkanpada masa sekarang(Harahap \& Surya, 2017). Salah satu model yang dapat digunakan misalnya model pembelajaran kooperatif, merupakan pembelajaran yang melatih diri siswa untuk lebih berani lagi dalam berdiskusi dan mengungkapkan pendapat sesuai dengan argumen materi pembelajarannya (Saddhono, 2016), pembelajaran model kooperatif yang digunakan adalah tipeinside outside circle.

Model Pembelajaran Kooperatif tipe Inside Outside Circle hadir dalam dunia pendidikan khususnya dalam pembelajaran di kelas memberikan suasana baru dalam proses pembelajaran. Model Kooperatif Tipe Inside Outside Circle adalah model pembelajaran yang dikembangkan oleh Spencer Kagan untuk memberikan kesempatan pada siswa agar saling 
berbagi informasi pada saat yang bersamaan.(Yuliana et al., 2018)

Model pembelajaran inside outside circle dikembangkan pertama kali oleh Spencer Kagan (1990). (Wahyudi \& Marwiyanti, 2017)mengatakan bahwa "Inside Outside Circle adalah model pembelajaran dengan sistem lingkaran kecil dan lingkaran besar, dimana siswa saling berbagi informasi pada saat yang bersamaan, dengan pasangan yang berbeda dengan singkat dan teratur". Model inimemberikan kesempatan kepada siswa untuk saling berbagi informasi dalam waktu yang bersamaan sehingga dapat membekali siswa untuk berbagi informasi dilingkunganya (Haryanti, 2016). Model pembelajaran ini paling cocok digunakan untuk bahan pengajaran yang bersifat membutuhkan pertukaran pikiran dan informasi antarsiswa serta siswa memiliki banyak kesempatan untuk mengolah informasi dan meningkatkan keterampilan berkomunikasi(Jauhar, Kadir, \& Wahyu, 2017)

Menurut(Azhary, Suwignyo, \& Hasanah, 2013) bahwa keunggulan model pembelajaran ini adalah adanya struktur yang jelas dan memungkinkan siswa untuk berbagi informasi dengan pasangan yang berbeda secara singkat dan teratur. Selain itu, model pembelajaran tipe Inside Outside Circle memberikan banyak kesempatan pada siswa untuk mengolah informasi dan meningkatkan pemahaman. Maka berdasarkan uraian di atas diduga bahwa model pembelajaran Inside Outside Circle dapat meningkatkan pemahamansiswa.

Penelitian sebelumnya pernah dilakukan kooperatif tipe lainnya sepertiindex card match oleh (Syahrir, 2017) yang merupakan model yang dilakukan berpasangan yang dapat membangkitkan keaktifan siswa dengan hasil yang signifikan terhadap hasil belajar siswa. Kooperatif lainnya yang dilakukan oleh (Harahap \& Surya, 2017)model pembelajarantipetwo stay two stray yang merupakan pembelajaran yang mengarahkan siswa untuk lebih aktif memproses informasi baik dalam diskusi melalui seorang teman sekelompoknya dengan mendapat interaksi antara hasil dengan model pembelajaran tersebut. Selanjutnya (Boleng, 2014) menyatakan penggunaan pembelajaran kooperatif tipe Script and Think-Pair-Share menghasilkan pengaruh dan meningkat keterampilan berpikir kritis siswa. Di level sekolah menengah atas kooperatif juga bisa dilakukan seperti yang diterapkan oleh (Nursyamsi \& Corebima, 2016)pembelajaran kooperatif tipe Numbered Heads Together (NHT) diperoleh dengan hasil yang baik terbukti terdapat pengaruh yang signifikan setelah dilakukan analisis perhitungan anova dengan persentase $24 \%$ lebih baik di bandingkan pembelajaran lainnya.Dari paparan diatas keterbaruan penelitian ini yang dibangkitkan adalah tipe kooperatif yang lainnya, yakni pembelajarantipe Inside Outside Circle.Pembelajaran ini memiliki pengaruh yang signifikan (Priyanto, 2017) yang diterapkan pada mata pelajaran IPS dengan melibatkan media kartu pintar. Di kelompok siswa SMP mata pelajaran IPS yang lain pembelajaran tipe Inside Outside Circleyang diterapkan oleh (Sri Yunita Ningsih, 2017)dengan hasil yang baik dan memiliki pengaruh yang baik terhadap hasil belajar siswa. Ranah yang lain, perangkat pembelajaran yang menggunakan model pembelajaran tipe Inside Outside Circleyang diujikan oleh (Astutiningrum, Hapsari, \& Purwanta, 2016) mendapatkan hasil yang baik dengan pembuktian dari hasil respon siswa lebih tinggi persentasenya dibandingkan persentase di tanpa menggunakan model pembelajaran tipe Inside Outside Circle. Selain keunggulan yang terpapar diatas adanya struktur yang jelas menjadikan pembelajaran ini lebih mendapatkan kesempatan siswa mengolah informasi lebih tinggi.

\section{METODE PENELITIAN}

Penelitian ini dilaksanakan di SMA Negeri 6 Pontianak. Sampel pada penelitian ini adalah siswa pada kelas XB dan kelas XE dengan jumlah masingmasing kelas adalah 32 siswa. Bentuk penelitian yang digunakan dalam penelitian adalah Quasi Experimental(Qusyairi \& Sakila, 2018). Design dengan rancangan penelitian two group posttest only(Mulyatiningsih, 2011)yaitu mencari suatu hubungan lebih dari satu variabel tentang pengaruh penerapan model pembelajaran inside outside circle terhadap hasil oleh guru geografi SMA Negeri 6 Pontianak.

Data yang dikumpulkan dalam penelitian ini adalah hasil belajar siswa dengan menggunakan rumus rata-rata atau mean dengan rumus sebagai berikut :

$$
\bar{x}=\frac{\sum X}{N}
$$

Sedangkan untuk menghitung pengaruh penerapan model pembelajaran inside outside circle pada siswa kelas X SMA Negeri 6 Kota Pontianak, maka terlebih dahulu dilakukan perhitungan terlebih dahulu dilakukan beberapa perhitungan, yang dimana perhitungannya sebagai berikut :

a. Menguji Normalitas dengan uji Lilliesfors

b. Jika kedua kelompok berdistribusi normal, maka dilanjutkan dengan mengetes homogenitas variansnya.

Diuji dengan menggunakan:

$\mathrm{F}_{\text {hitung }}=\frac{\text { Varian terbesar }}{\text { Varian terkecil }}$ 
c. Jika datanya berdistribusi normal dan datanya homogen maka dilanjutkan dengan uji $t$,jika tidak normal maka uji $U$ Mann Whitney yang akan digunakan untuk menganalisis data hasil yang didapatkan,untuk menggunakan rumus $\mathrm{uji}-\mathrm{t}$ pooled varian dengan rumus:

$$
t=\frac{\bar{X}_{1}-\bar{X}_{2}}{\sqrt{\frac{\left(n_{1}-1\right) s_{1}^{2}+\left(n_{2}-1\right) s_{2}^{2}}{n_{1}+n_{2}-2}\left(\frac{1}{n_{1}}+\frac{1}{n_{2}}\right)}}
$$

\section{HASIL DAN PEMBAHASAN}

Penelitian ini dilakukan sejak bulan Agustus sampai November meliputi tahap perijinan, pelaksanaan, pengumpulan data dan analisis data. Berikut hasil penelitian yang didapat peneliti di lapangan:

1. Rata-rata hasil belajar siswa kelas control atau tidak diterapkan model pembelajaran inside outside circle mata pelajaran geografi kelas $\mathrm{X}$ SMA N 6 Pontianak dengan nilai rata-rata posttest sebagai berikut:

$$
\bar{x}=\frac{\sum x}{N}=\frac{2434}{36}=67,6
$$

2. Rata-rata hasil belajar siswa kelas eksperimen atau kelas yang diterapkan model pembelajaran inside outside circle mata pelajaran geografi kelas X SMA Negeri 6 Pontianak dengan nilai post testsebagai berikut :

$$
\bar{x}=\frac{\sum x}{N}=\frac{2545}{36}=70,6
$$

Berdasarkan hasil konsultasi nilai kelas control dan kelas eksperimen siswa tersebut, dapat disimpulkan bahwa nilai rata-rata kelas control sebesar 67,6 dan nilai rata-rata kelas eksperimen sebesar 70,6. Dari nilai rata-rata keduanya secara deskriptif menunjukkan ada peningkatan nilai rata-rata hasil belajar siswa. Peneliti berasumsi terdapat pengaruh dari penerapan model pembelajaran inside outside circle.

3. Untuk menjawab sub masalah ketiga,Apakah terdapat pengaruh penerapan model pembelajaran inside outside circle terhadap hasil belajar siswa mata pelajaran geografi kelas $\mathrm{X}$ SMAN 6 Pontianak, terlebih dahulu dilakukan beberapa perhitungan, yang dimana perhitungannya sebagai berikut :

a. Uji liliefors

Hipotesis statistik uji Liliefors dengan menggunakan SPSS sebagai berikut:

$\mathrm{H}_{0}=$ Data berdistribusi Normal

$\mathrm{H}_{\mathrm{a}}=$ Data Tidak Berdistribusi normal
Hasil uji liliefors menyatakan hasil Sig Kolmogorov-Smirnova $0,000<0,05$, maka Ho di tolak dan dapat disimpulkan bahwa distribusi data kelompok eksperimen dan kontrol adalah tidak normal.

b. Uji Homogenitas

Hipotesis statistik uji homogenitas dengan menggunakan SPSS sebagai berikut:

H0 = Data berdistribusi Homogen

$\mathrm{Ha}=$ Data Tidak Berdistribusi Homogen

Berdasarkan data output di ats di ketahui nilai signifikan (Sig) Based on Mean adalah sebesar 0,925>0,05, sehingga dapat disimpulkan bahwa varians kelompok eksperimen dan kontrol adalah homogen.

c. Uji Hipotesis

Berdasarkan perhitungan uji Lilifors dan Uji Homogen(uji F) pada data kelas kontrol dan kelas eksperimenpada siswa kelas X SMA N 6 Pontianak bahwa data tersebut berdistribusi tidak normal dan bersifat homogen. Sehingga untuk melakukan pengujian hipotesis menggunakan statistik non parametik, yaitu menggunakan rumus $U$ Mann Whitney. $U$ Mann Whitney Test adalah uji non parametris yang digunakan untuk mengetahui perbedaan median 2 kelompok bebas apabila skala data variabel terikatnya adalah ordinal atau interval/ratio tetapi tidak berdistribusi normal. Hasil dari Uji $U$ Mann Whitney ini menggunakan aplikasi SPSS.Adapun hasilnya sebagai berikut :

Hipotesis uji U Mann Whitneyantara lain:

$\mathrm{H}_{0}=$ Tidak terdapat pengaruh antar variabel

$\mathrm{H}_{\mathrm{a}}=$ Terdapat pengaruh antar variabel

\begin{tabular}{lr}
\hline \multicolumn{2}{c}{ Test Statistics $^{\mathbf{a}}$} \\
\hline Mann-Whitney U & \multicolumn{1}{c}{ Hasil_Belajar } \\
Wilcoxon W & 460,500 \\
Z & 1126,500 \\
Asymp. Sig. (2-tailed) & $-2,206$ \\
Grouping Variable: Kelas &, 027 \\
\hline \multicolumn{2}{c}{ Tabel 1. Tes Statistik }
\end{tabular}

Berdasarkan data output Uji U Mann Whitney diatas dengan hasil Asymp Sig. (2-tailed) 0,027 dan nilai probabilitas sebesar 0,050, maka hasilnya adalah $\mathrm{H}_{\mathrm{o}}$ ditolakdengan hasil uji Asymp Sig. (2-tailed) = $0,027<0,050$. Yang berarti dengan demikian dapat disimpulkan bahwa terdapat pengaruh penerapan model pembelajaran inside outside circle terhadap hasil belajar siswa mata pelajaran geografi pada siswa kelas X SMA N 6 Pontianak 
Penelitian ini dimulai dengan melakukan observasi awal dengan tujuan untuk mencari permasalahan pada pembelajaran geografi di SMA Negeri 6 Pontianak. Peneliti melihat hasil belajar siswa pada mata pelajaran geografi kelas $\mathrm{X}$ masih kurang memuaskan karena masih ada beberapa siswa yang belum mencapai nilai KKM. Setelah dilakukan observasi langsung di kelas, ditemukan bahwa siswa terlihat tidak tertarik untuk mengikuti pembelajaran di kelas. Hal ini disebabkan karena guru menerapkan metode ceramah dan komunikasi satu arah sehingga siswa cenderung bosan dan memilih melakukan kegiatan lain. Hal ini tentu saja menyebabkan siswa tidak bisa mendapat informasi dari penjelasan guru yang berdampak pada hasil belajar mereka yang rendah.

Setelah berdiskusi dan meminta izin kepada guru mata pelajaran geografi yaitu bapak Dwi Wahyu Febrianto, S. Pd, peneliti sepakat untuk melakukan penelitian berupa eksperimen penerapan model pembelajaran yang lebih komunikatif dan variatif yang mana diharapkan dapat meningkatkan efektivitas pembelajaran yang pada akhirnya dapat meningkatkan hasil belajar siswa kelas $\mathrm{X}$ pada mata pelajaran geografi.

Model pembelajaran yang dipilih yaitu inside outside circle. Hakikat dari pelaksanaan model pembelajaran ini adalah agar siswa terlibat secara langsung dalam proses pembelajaran. Siswa dituntut untuk berbagi informasi kepada siswa lainnya secara bergantian. Hal ini membuat siswa lebih termotivasi untuk memungkinkan berinteraksi dengan orang laindan menemukan informasi sebanyak mungkin agar bisa berbagi kepada siswa lain secara optimal(Sudrajad \& Wijaya, 2016). Sebaliknya, mereka akan malu jika tidak berperan aktif karena seluruh siswa akan mendapat giliran dalam pembagian informasi.

Selain meningkatkan motivasi siswa, model pembelajaran ini memberikan kesempatan yang luas seluas-luasnya kepada siswa untuk berbagi informasi yang mungkin mereka ketahui dari luar pelajaran. Hal ini dapat membuat suasana kelas menjadi lebih hidup dan bermakna namun tentu harus dibarengi dengan pengawasan dari guru mata pelajaran agar tema pembelajaran tidak keluar jalur.

Penelitian ini menggunakan model eksperimen dengan bentuk quasi-experiment. Subjek penelitian dibagi ke dalam 2 kelompok yaitu kelas kontrol dan kelas eksperimen dimana akan diterapkan model pembelajaran inside outside circle. Hasil penelitian adalah perbandingan darihasil belajar kelas control dan kelas eksperimen sehingga dapat diketahui efek atau pengaruh dari model pembelajaran inside outside circle terhadap hasil belajar siswa.
Setelah dilakukan eksperimen terhadap kelas eksperimen dan diberikan tes untuk melihat hasil belajar siswa, ditemukan bahwa terdapat peningkatan perbedaan hasil belajar siswa setelah diberikan model pembelajaran inside outside circle. Pada kelas control, rata-rata hasil belajar siswa adalah 67,6 dengan kategori sedang sedangkan pada kelas eksperimen ratarata hasil belajar siswa adalah 70,6 dengan kategori tinggi. Sedangkan perhitungan uji $U$ Mann WhitneyAsymp Sig. (2-tailed) $=0,027<0,050$.

Berdasarkan hasil perhitungan penelitian, ditemukan bahwa model pembelajaran inside outside circle memberikan efek atau dampak terhadap peningkatan hasil belajar siswa. Hal ini disebabkanmodel ini dapat memberikan kesempatan kepada siswa untuk saling berbagi informasi melalui diskusi terbuka sehingga minat siswa untuk terlibat aktif juga meningkat.

Model pembelajaran ini dapat diterapkan untuk beberapa mata pelajaran salah satunya mata pelajaran ilmu pengetahuan sosial, selain itu model pembelajaran ini paling cocok digunakan untuk bahan pengajaran yang bersifat membutuhkan pertukaran pikiran dan informasi antarsiswa serta siswa memiliki banyak kesempatan untuk mengolahinformasi dan meningkatkan keterampilan berkomunikasi.

\section{KESIMPULAN}

Kesimpulan secara khusus mengenai sub masalah dalam penelitian ini adalah sebagai berikut:

1. Nilai rata-rata hasil belajar siswa pada kelas control mata pelajaran geografi kelas X SMA Negeri 6 Pontianak sebesar 67,6 dengan kategori sedang.

2. Nilai rata-rata hasilbelajarsiswa pada kelas eksperimen pada mata pelajaran geografi kelas X SMA Negeri 6 Pontianak sebesar 70,6 dengan kategori baik.

3. Terdapat pengaruh penerapan model pembelajaran Inside Outside Circle terhadap hasil belajar siswa pada mata pelajaran geografi kelas X SMA Negeri 6 Pontianak dengan nilai hasil uji $U$ Mann Whitney Asymp Sig. (2-tailed) = 0,027<0,050.

Secara umum dari paparan kesimpulan diatas hipotesis sesuai dengan yang diharapkan yakni H0 ditolak dengan hasil terdapat pengaruh penggunaan model pembelajaran inside outside circledengan hasil belajar siswa.

Saran bagi peneliti selanjutnya untuk kedepannya lebih diperhatikan lagi dan difokuskan lagi bagian langkah-langkah dalam model pembelajaran ini demi meminimalisir kesalahan bahkan kegagalan yang tidak diharapkan. 


\section{Daftar Pustaka}

Astutiningrum, D., Hapsari, E. D., \& Purwanta. (2016). Peningkatan Parenting Self Efficacy Pada Ibu Pasca Seksio Sesaria Melalui Konseling ( Improving Parenting Self Efficacy after Caesarean Section through Counselling ). Jurnal Ners, 11(1), 134-141. https://doi.org/10.1016/j.str.2015.10.016

Azhary, Y. A., Suwignyo, H., \& Hasanah, M. (2013). Penerapan Pembelajaran Kooperatif Model Inside-Outside Circle Untuk Meningkatkan Hasil Belajar Apresiasi Dongeng Siswa Kelas VIIC MTsN Juwet Ngronggot Nganjuk. PBSIOnline, l(1), 66-74.

Boleng, D. T. (2014). The Effect of Cooperative Learning on Psychological and Social Traits Among Under- graduate Students. Social Behavior and Person- ality. Jornal Pendidikan Sains, 2(2), 76-84.

Harahap, K. A., \& Surya, E. (2017). Application of Cooperative Learning Model With Type of Two Stay Two Stray to Improve Results of Mathematics Teaching. International Journal of Sciences: Basic and Applied Research (IJSBAR), 33(2), 156-165.

Haryanti, Y. D. (2016). Peningkatan Hasil Belajar Dengan Menggunakan Model Cooperative Learning Type Inside-Outside Circle. Jurnal Cakrawala Pendas, 2(2), 94-104. https://doi.org/10.31949/jcp.v2i2.337

Jauhar, S., Kadir, A., \& Wahyu, W. (2017). Penerapan Model Pembelajaran Inside Outside Circle Dalam Meningkatkan Hasil Belajar IPS Siswa Kelas IV SD Negeri 215 Kading Kecamatan Barebbo Kabupaten Bone. JIKAP PGSD: Jurnal Ilmiah Ilmu Kependidikan, 1(1), 34. https://doi.org/10.26858/jkp.v1i1.5067

Malasari, P. N., Nindiasari, H., \& Jaenudin. (2017). Preface: International Conference on Recent Trends in Physics (ICRTP 2016). Journal of Physics: Conference Series, 812(1), 1-6. https://doi.org/10.1088/1742-6596/755/1/011001

Mulyatiningsih, E. (2011). Riset terapan bidang pendidikan dan teknik (1st ed.; A. Nuryanto, ed.). yogyakarta: UNY Pres.

Nursyamsi, S. Y., \& Corebima, A. D. (2016). The Effect of Numbered Heads Together (NHT) Learning Strategy on The Retention of Senior High School Students in Muara Badak, East Kalimantan, Indonesia. European Journal of Education Studies, 2(5), 47-58. https://doi.org/10.5281/zenodo.154450 European Priyanto, W. (2017). Kolaborasi Model Pembelajaran Inside Outside Collaboration Between Inside
Outside Circle Model. Jurnal Edudikara, 2(3), 217-224.

Qusyairi, L. A. H., \& Sakila, J. (2018). Pengaruh Model Cooperative Learning Tipe Inside-Outside Circle (IOC) terhadap Prestasi Belajar dengan Memperhatikan Minat Belajar Matematika. Palapa, 6(1), 34-49. https://doi.org/10.36088/palapa.v6i1.57

Saddhono, K. (2016). The argumentative writing skill with multicultural awareness in Indonesian Language for Foreign Learners. International Scientific Researches Journal, 72(4), 108-116.

Sri Yunita Ningsih, S. A. (2017). Penerapan Model Pembelajaran Inside Outside Circle Terhadap Pemahaman Konsep Siswa. Matematics Education and Science, 2(2), 88-94. Retrieved from https://ejurnal.bunghatta.ac.id/index.php?Journal $=$ JFKIP $\&$ page $=$ article $\&$ op $=$ viewfile $\&$ path []$=308$ $3 \&$ path[] $=2664$

Sudrajad, M., \& Wijaya, A. (2016). the Effectiveness of Inside-Outside Circle Method By Using Cue Card for Students' Speaking Ability At Seventh Graders. Journal of English Educators Society, l(1), 59-70. https://doi.org/10.21070/jees.v1i1.146

Syahrir. (2017). Application of Cooperative Learning Model Index Card Composition and Composition Functions of Functions Invers in Man 1 Mataram. Pendidikan Matematika FKIP Univ. Muhammadiyah Metro, 6(3), 414-420.

Wahyudi, D., \& Marwiyanti, L. (2017). Penerapan Model Pembelajaran Inside Outside Circle Dalam Mata Pelajaran Akidah Akhlak. Jurnal MUDARRISUNA: Media Kajian Pendidikan Agama Islam, 7(2), 267. https://doi.org/10.22373/jm.v7i2.2369

Yuliana, L., Barlian, I., \& Jaenuddin, R. (2018). Pengaruh Model Pembelajaran Kooperatif Tipe Inside Outside Circle Terhadap Keaktifan Belajar Peserta Srijaya Negara Palembang. Jurnal Profit, 5(1), 17-27. 
J U R N Sumal Pendidikan Ilmu Pengetahuan Sosial Indonesia

A D Dolum 5 Nomor 1 Bulan Maret 2020 Page 14 - 19

p-ISSN: 2477-6254 e-ISSN: 2477-8427 